\title{
Analisis Faktor-Faktor Penentu Mutu Pendidikan Sekolah Dasar Negeri di Kota Manado Menggunakan Analisis Faktor
}

\author{
Chirdy Onibala ${ }^{1}$, Marline Paendong ${ }^{2}$, Djoni Hatidja ${ }^{3}$ \\ ${ }^{1}$ Program Studi Matematika, FMIPA, UNSRAT Manado, Chirdy_onibala@yahoo.com. \\ ${ }^{2}$ Program Studi Matematika, FMIPA, UNSRAT Manado, Marline_paendong@yahoo.com. \\ ${ }^{3}$ Program Studi Matematika, FMIPA, UNSRAT Manado, HatidjaD@yahoo.com.
}

\begin{abstract}
Abstrak
Penelitian dilakukan untuk mengetahui faktor-faktor penentu mutu Pendidikan Sekolah Dasar Negeri di kota Manado, mengetahui indikator-indikator yang bersifat dominan terhadap mutu pendidikan Sekolah Dasar Negeri di kota Manado dan penilaian orang tua murid terhadap mutu pendidikan Sekolah Dasar. Penelitian dilakukan di kota Manado dengan jumlah data responden yang di ambil sebanyak 43 Sekolah Dasar Negeri dari jumlah populasi Sekolah sebanyak 75. Dengan menggunakan Analisis faktor, hasil penelitian ini menunjukan jumlah faktor keragaman penentu mutu pendidikan Sekolah Dasar Negeri di Kota Manado sebesar 75,78\% dengan faktor standar sarana dan prasarana memiliki kontribusi sebesar $37.319 \%$.
\end{abstract}

Kata kunci : Analisis Faktor, Mutu Pendidikan Sekolah Dasar Negeri.

\section{Analysis of Determinant Factors of Education Quality at Public Primary Schools in Manado Using Factor Analysis}

\begin{abstract}
Research was conducted to find determinant factors of education Quality Primary School in Manado city, find indicators that are dominant of Education Quality in Public Primary School in Manado city and parental assessment of Education Quality in Public Primary Schools. Research conducted in Manado city by using Factor Analysis. Research result showing 75,78\% Education Quality in Public Primary School in Manado city with standard factors facilities and infrastructure hava contributed $37.32 \%$.
\end{abstract}

Keyword : Factor Analysis, Education Quality at Public Primary Schools.

\section{Pendahuluan}

Faktor pengetahuan dan pendidikan selalu menjadi bahan yang penting untuk setiap manusia dari dulu, saat ini hingga di masa yang akan datang. Karena dengan pendidikan setiap orang dapat memperoleh kehidupan yang lebih baik dan semakin maju. Setiap negara yang sudah maju maupun yang belum maju dalam hal perekonomian dan teknologi informasi sangat membutuhkan pengetahuan dan pendidikan yang baik agar dapat membangun negara ke arah yang lebih baik. Negara Indonesia meyakini bahwa pengetahuan dan pendidikan merupakan sektor penting dalam pembangunan negara. Sebab dengan pengetahuan dan pendidikan yang dimiliki setiap warga negara dapat menjamin negara untuk maju dan lebih baik.

Sangat disayangkan bila semakin banyak lembaga atau instansi yang menawarkan tambahan waktu belajar bagi para siswa-siswi untuk belajar diluar sekolah. Ada juga sebagian besar dari orang tua masih membutuhkan tenaga privat belajar untuk anaknya, yang seharusnya telah diperoleh dari sekolah dan bisa dilatih kembali oleh orang tua di rumah. Ini menunjukan bahwa perlu mendapat perhatian sehingga hal seperti ini bisa ada diluar sekolah. Dan oleh karena itu, ini memberikan sebuah bukti bahwa ada beberapa mutu pendidikan di sekolah yang tidak terselenggarakan dengan maksimal.

Indikator kunci pencapaian 8 Standar Nasional pendidikan Sekolah Dasar yaitu meliputi : Standar Sarana dan Prasarana, Standar isi, Standar Proses, Standar penilaian, Standar kompetensi 
kelulusan, Standar pengelolaan, Standar pendidikan dan tenaga kependidikan, Standar pembiayaan. [1]. Dengan menggunakan metode analisis faktor, indikator-indikator yang menjadi penentu dapat dilihat, dengan begitu mutu pendidikan Sekolah Dasar Negeri yang perlu ditingkatkan dapat diketahui.

\section{Analisis Faktor}

Analisis faktor adalah salah satu analisis statistika multivariat yang pertama kali dikenalkan oleh Spearman pada tahun 1904. Analisis faktor di maksudkan untuk menemukan faktor yang terdiri dari beberapa variabel asli yang memiliki korelasi didalamnya. Analisis faktor dapat juga digunakan untuk mengidentifikasi struktur hubungan antar variabel ataupun antar responden. Analisis faktor juga bertujuan untuk mereduksi data.

Tujuan dari analisis faktor adalah untuk menggambarkan hubungan-hubungan kovarian antara beberapa variabel yang mendasari tetapi tidak teramati, kuantitas acak yang disebut faktor, [2]. Vektor random teramati $X$ dengann $p$ komponen, memiliki rata-rata $\boldsymbol{\mu}$ dan matrik covarian $\sum$. Model analisis faktor adalah sebagai berikut :

$$
\begin{array}{r}
X_{1}-\mu_{1}=\ell_{11} F_{1}+\ell_{12} F_{2}+\ldots .+\ell_{1 m} F_{m}+\varepsilon_{1} \\
X_{p}-\mu_{p}=\ell_{p 1} F_{1}+\ell_{p 2} F_{2}+\ldots .+\ell_{p m} F_{m}+\varepsilon_{p}
\end{array}
$$

Atau dapat ditulis dalam notasi matrik sebagai berikut :

$$
\boldsymbol{X}_{p x l}=\boldsymbol{\mu}_{(p x l)}+\boldsymbol{L}_{(p x m)} \boldsymbol{F}_{(m x l)}+\boldsymbol{\varepsilon}_{p x l}
$$

dengan :

$$
\begin{array}{ll}
\mu_{i}=\text { rata-rata variabel } & F_{j}=\text { common faktor ke- } j \\
\varepsilon_{i}=\text { faktor spesifik ke }-i & \ell_{i j}=\text { loading dari variabel ke }-i \text { pada faktor ke- } j
\end{array}
$$

Bagian dari varian variabel ke $-i$ dari $m$ common faktor disebut komunalitas ke $-i$ yang merupakan jumlah kuadrat dari loading variabel $\mathrm{ke}-i$ pada $m$ common faktor [2], dengan rumus :

$$
h_{i}^{2}=\ell_{i 1}^{2}+\ell_{i 2}^{2}+\ldots .+\ell_{i m}^{2}
$$

Tujuan analisis faktor adalah menggunakan matriks korelasi hitungan yaitu sebaagai berikut :

1. Mengidentifikasi jumlah terkecil dari faktor umum yang mempunyai penjelasan terbaik atau menghubungkan korelasi diantara variabel indikator.

2. Mengidentifikasi, melalui faktor rotasi, solusi faktor yang paling masuk akal.

3. Estimasi bentuk dan struktur loading, Communality dan varian unik dari indikator.

4. Intrepretasi dari faktor umum.

5. Jika perlu, dilakukan estimasi faktor skor. [2].

Jadi dengan menggunakan analisis faktor, kita dapat menemukan faktor-faktor yang dapat mewakili variabel-variabel asli.

\subsection{Model Matematika Analisis Faktor}

Misalkan variabel acak $\mathrm{X}$ dengan $\mathrm{p}$ komponen memiliki rataan $\mu$ dan peragam (covarian) matriks $\Sigma$. Model faktor dibentuk agar x menjadi linear dan bergantung dengan beberapa peubah acak yang tidak dapat terobservasi, yaitu $\mathrm{F}_{1}, \mathrm{~F}_{2}, \mathrm{~F}_{3}, \ldots, \mathrm{F}_{n}$ (faktor bersama) yang disebut faktor umum, faktor loading (loading factor) ı dan $\mathrm{p}$ sumber keragaman $\varepsilon_{1}, \varepsilon_{2}, \varepsilon_{3}, \ldots, \varepsilon_{n}$ yang disebut error atau galat atau faktor-faktor spesifik (faktor khusus) [3]. Sehinnga persamaan umum analisis faktor dapat dirumuskan sebagai berikut.

$$
\begin{gathered}
X-\mu=L F+\varepsilon \\
X_{1}-\mu_{1}=l_{11} F_{1}+l_{12} F_{2}+l_{13} F_{3}, \ldots,+l_{1 n} F_{n}+\varepsilon_{p} \\
X_{2}-\mu_{2}=l_{21} F_{1}+l_{22} F_{2}+l_{23} F_{3}, \ldots,+l_{2 n} F_{n}+\varepsilon_{p} \\
X_{p}-\mu_{p}=l_{p 1} F_{1}+l_{p 2} F_{2}+l_{p 3} F_{3}, \ldots,+l_{p n} F_{n}+\varepsilon_{p}
\end{gathered}
$$




\subsection{Langkah-langkah Melakukan Analisis Faktor}

Menurut [5], langkah pertama dalam analisis faktor adalah merumuskan masalah faktor analisis dan mengidentifikasi atau mengenali variabel-variabel asli yang akan dianalisis faktor. Kemudian suatu matriks korelasi dari variabel-variabel ini dibentuk dan metode analisis faktor dipilih. Peneliti menemukan banyaknya faktor yang disarikan (extracted) dari variabel yang banyak tersebut dan metode rotasi yang akan digunakan. Langkah berikutnya harus mengiterpretasikan faktor hasil rotasi.

\subsection{Merumuskan Masalah}

Merumuskan masalah meliputi beberapa hal :

- Tujuan analisis faktor teridentifikasi.

- Variabel yang akan dipergunakan dalam analisis faktor harus dispesifikasi berdasarkan penelitian sebelumnya, teori dan pertimbangan dari peneliti.

- Pengukuran variabel berdasarkan skala interval atau rasio.

- Banyaknya elemen sampel (n) harus cukup memedai atau memenuhi sebagai keterwakilan populasi. [3]

\section{Uji Kaiser Meyer Oikin (KMO)} difaktorkan.

Uji KMO untuk mengetahui apakah semua data yang telah terambil telah cukup untuk Statistik Uji KMO :

$$
\mathrm{KMO}=\frac{\sum_{i=1}^{p} \sum_{j=1}^{p} r_{i j}^{2}}{\sum_{i=1}^{p} \sum_{j=1}^{p} r_{i j}^{2}+\sum_{i=1}^{p} \sum_{j=1}^{p} a_{i j}^{2}}
$$

$i=1,2,3, \ldots, p$ dan $\mathrm{j}=1,2, \ldots, p$

$r_{i j}=$ Koefisien korelasi antara variabel $i$ dan $j$

$\mathrm{a}_{\mathrm{ij}}=$ Koefisien korelasi parsial antara variabel $i$ dan $j$

Apabila nilai KMO lebih besar dari 0,5 maka terima Ho, sehingga dapat disimpulkan jumlah data telah cukup difaktorkan [5].

\subsection{Uji Bartlett}

Uji Bartlett bertujuan untuk mengetahui apakah terdapat hubungan antar variabel dalam kasus multivariat. Jika variabel $\mathrm{X}_{1}, \mathrm{X}_{2}, \ldots, \mathrm{X}_{\mathrm{p}}$ independent (bersifat saling bebas), maka matriks korelasi antar variabel sama dengan matriks identitas. Sehingga untuk menguji kebebasan antar variabel ini, uji Bartlett menyatakan hipotesis sebagai berikut :

$\mathrm{H}_{0}: \boldsymbol{\rho}=\mathbf{I}$

$\mathrm{H}_{1}: \boldsymbol{\rho} \neq \mathbf{I}$

$$
\begin{array}{ll}
\bar{r}_{k}=\frac{1}{p-1} \sum_{i=1}^{p} r_{i k} & \hat{\gamma}=\frac{(p-1)^{2}\left[1-(1-\bar{r})^{2}\right]}{p-(p-2)(1-\bar{r})^{2}} \\
k & =1,2, \ldots, p \\
\bar{r} & =\frac{2}{p(p-1)} \sum \sum_{i<k} r_{i k}
\end{array}
$$

Dengan :

$r_{k}=$ rata-rata elemen diagonal pada kolom atau baris ke $k$ dari matrik $\mathrm{R}$ (matriks korelasi)

$\bar{r}$ = rata-rata keseluruhan dari elemen diagonal. [5] 


\section{Menentukan Metode Analisis Faktor}

Dalam principal component analysis jumlah varian dalam data dipertimbangkan. Diagonal matriks korelasi terdiri dari angka satu (1) dan full variance dibawa kedalam matrikks faktor. Principal component analysis direkomendasikan kalau hal pokok ialah menentukan bahwa banyaknya faktor harus minimum dengan memperhitungkan varian maksimum dalam data untuk dipergunakan didalam analisis multivariat lebih lanjut. Faktor-faktor tersebut dinamakan principal component.

Dalam common factor analysis, faktor diestimasi berdasarkan pada common variance, communalities dimasukan didalam materiks korelasi. Metode ini dianggap tepat kalau tujuan utamanya ialah mengenali atau mengidentifikasi dimensi yang mendasari common variance yang menarik perhatian. Metode ini juga dikenal sebagai principal axis factor-ing [3].

\subsection{Rotasi Faktor}

Hasil yang penting dari analisis faktor ialah apa yang disebut matriks faktor pola. Matriks faktor berisi koefisien yang digunakan untuk mengekspresikan variabel yang dibekukan dinyatakan dalam faktor. Rotasi faktor ini merupakan transformasi orthogonal dari factor loadings.

$\mathrm{L}$ '= LT, dimana $\mathrm{T}^{\prime} \mathrm{T}=1$

Didalam melakukan rotasi faktor, kita menginginkan agar setiap faktor mempunyai muatan (loading) atau koefisien yang tidak 0 atau yang signifikan untuk beberapa variabel saja.

Ada beberapa rotasi faktor yang biasa digunakan :

- Varimax method

- Equamax method

- Quartimax method

\subsection{Interpretasi Faktor}

Interpretasi faktor digunakan untuk mengenali variabel yang muatannya besar pada faktor sama. Faktor tersebut kemudian bisa diinterpretasikan dalam variabel yang mempunyai loading tinggi padannya. Manfaat lainnya ialah membantu interpretasi dengan plot variabel menggunakan factor loading sebagai koordinat $\left(\mathrm{F}_{1}\right.$ dan $\left.\mathrm{F}_{2}\right)$. Variabel pada ujung atau akhir suatu sumbu ialah variabel yang mempunnyai loading tinngi hanya ada pada salah satu faktor $\left(F_{1}\right.$ dan $\left.F_{2}\right)$. Sehingga dapat disimpulkan bahwa faktor tersebut terdiri dari variabel-variabel yang dekat dengan titik asal (perpotongan sumbu $\mathrm{F}_{1}$ dan $\mathrm{F}_{2}$ ) mempunyai loading rendah pada kedua faktor [4].

\section{Metodologi Penelitian}

\subsection{Sumber Data}

Penelitian dilakukan pada bulan Juni 2014. Tempat penelitian dilakukan di kota Manado. Data yang digunakan yaitu data sekunder yang berisi indikator-indikator dalam mutu pendidikan Sekolah Dasar Negeri di Kota Manado. Data data dikumpul melalui kuisoner yang diisi oleh Kepala Sekolah dari sekolah-sekolah terpilih di Kota Manado ditambah dengan orang tua dari salah satu murid sekolah tersebut. Pengambilan sampel yang digunakan adalah Sample random sampling. Populasi yang dijadikan objek penelitian berjumlah 75 Sekolah. Keterangan 75 Sekolah Dasar Negeri di Kota Manado dapat dilihat pada Lampiran 1.

Jumlah sampel yang ditentukan dari banyaknya populasi sekolah menggunakan metode slovin, yaitu :

$$
\begin{aligned}
& \mathrm{n}=\frac{N}{1+N \cdot e^{2}} \quad \text { dengan : } \\
& \mathrm{n}=\text { Jumlah sampel } \\
& \mathrm{N}=\text { Jumlah populasi } \\
& \mathrm{e}=\text { Persen kelonggaran ketidaktelitian }(0,1)
\end{aligned}
$$

$\mathrm{n}=\frac{75}{1+75 .(0.1)^{2}}=42.857$

Jumlah sampel yang di ambil adalah sebanyak 43 Sekolah Dasar Negeri diikuti dengan orang tua siswa sebanyak 43 sebagai perbandingan. 


\subsection{Variabel Penelitian}

Tabel 1 : Indikator pertanyaan

\begin{tabular}{|c|c|c|c|c|c|}
\hline No & $\mathrm{X}$ & Variabel (VAR) & No & $\mathrm{X}$ & Variabel (VAR) \\
\hline 1 & 1 & Sarana dan Prasarana sekolah & 14 & 14 & Pencapaian peserta didik \\
\hline 2 & 2 & Kondisi sekolah & 15 & 15 & Pengembangan Potensi \\
\hline 3 & 3 & Kurikulum sekolah & 16 & 16 & Kinerja visi dan misi \\
\hline 4 & 4 & $\begin{array}{l}\text { Penyediaan kebutuhan dalam } \\
\text { pengembangan diri peserta didik }\end{array}$ & 17 & 17 & Perbaikan kinerja \\
\hline 5 & 5 & Silabus & 18 & 18 & Peningkatan hasil belajar \\
\hline 6 & 6 & RPP pembelajaran & 19 & 19 & Pengumpulan dan penggunaan data \\
\hline 7 & 7 & $\begin{array}{l}\text { Sumber belajar untuk } \\
\text { pembelajaran dapat diperoleh dan } \\
\text { digunakan secara tepat }\end{array}$ & 20 & 20 & $\begin{array}{l}\text { Pengembangan profesi bagi para } \\
\text { pendidik dan tenaga kependidikan }\end{array}$ \\
\hline 8 & 8 & $\begin{array}{l}\text { Penerapkan prinsip-prinsip } \\
\text { PAKEM/ CTL }\end{array}$ & 21 & 21 & Masyarakat sekitar \\
\hline 9 & 9 & Kebutuhan semua peserta didik & 22 & 22 & $\begin{array}{l}\text { Jumlah pendidik dan tenaga } \\
\text { kependidikan }\end{array}$ \\
\hline 10 & 1 & Prestasi sekolah & 23 & 23 & Pengelolaan Keuangan \\
\hline 11 & 11 & $\begin{array}{l}\text { Penilaian dalam bidang akademik } \\
\text { maupun non akademik. }\end{array}$ & 24 & 24 & Tambahan dukungan pembiayaan \\
\hline 12 & 12 & $\begin{array}{l}\text { Penilaian berdampak pada proses } \\
\text { belajar }\end{array}$ & 25 & 25 & Penjaminan kesetaraan akses \\
\hline 13 & 13 & Peran Orang tua & & & \\
\hline
\end{tabular}

Dengan Skala pengukuran :

- Tidak baik = 1

- Cukup baik $=2$

- Baik = 3

- Sangat baik = 4

\subsection{Analisis Data}

Prosedur analisis faktor adalah sebagai berikut :

1) Membentuk matriks korelasi yang terdiri dari indikator (n) dan jumlah responden (p) dengan ukuran ( $\mathrm{n} \times \mathrm{p}$ ).

2) Menghitung matriks korelasi antar indikator yang diobservasi menggunakan barttlet test of sphericity dan Kaiser-Mayer-Olkin (KMO) dimana KMO> 0,5

3) Menentukan indikator-indikator yang layak untuk analisis faktor dengan melihat nilai MSA $>0,5$.

4) Ekstraksi faktor

5) Rotasi faktor

6) Interpretasi hasil

Analisis data dilakukan dengan menggunakan bantuan software statistika.

\section{Hasil dan Pembahasan}

\subsection{Uji Validitas dan Reliabilitas}

Dalam penelitian ini menggunakan korelasi bivariat untuk menguji setiap indikator pertanyaan. Setelah data valid karena memiliki korelasi setiap item adalah 1, maka dilanjutkan dengan uji reliabilitas dimana kriterianya adalah instrument memiliki tingkat reliabilitas yang tinggi apabila memeliki nilai cronbach's alpha $(\alpha)>0,06$.

\subsection{Analisis faktor}

Variabel-variabel yang dianalisis dalam penelitian ini adalah Standar Sarana dan Prasarana SD / MI yang terdiri dari 2 item pertanyaan, standar isi yang terdiri dari 2 item pertanyaan, standar proses 6 item pertanyaan, standar penilaian yang terdiri dari 3 pertanyaan, standar kompetensi kelulusan SD yang terdiri dari 2 pertanyaan, standar pengelolaan yang terdiri dari 6 item 
pertanyaan, standar pendidik dan tenaga kependidikan yang terdiri dari 1 item pertanyaan dan standar pembiayaan yang terdiri dari 3 item pertanyaan. Sehingga total indikator adalah 25 pertanyaan. Jumlah sampel dan banyaknya item pertannyaan ini kemudian di buat dalam bentuk matriks korelasi dengan ukuran 25 x 43.

\subsubsection{Uji KMO dan Bartlett}

Variabel-variabel yang telah dibentuk dalam matriks selanjutnya diuji untuk mengukur kecukupan sampel dengan cara membandingkan besarnya koefisien korelasi yang diamati dengan koefisien parsialnya. Dalam hal ini digunakan uji KMO (Kaiser-Meyer-Olkin). Uji selanjutnya adalah uji Bartlett's test of sphericity yang tujuannya adalah untuk mengetahui apakah ada korelasi yang signifikan antar variabel. Berdasarkan hasil analis diperoleh output dari data variabel yang didapat dari kepala sekolah seperti Tabel 2. Proses uji juga dilakukan pada data orang tua siswa meliputi pada Tabel 3 .

Tabel 2.KMO and Bartlett's Test data Kepala Sekolah

\begin{tabular}{|l|l|r|}
\hline \multicolumn{2}{|l|}{ Kaiser-Meyer-Olkin Measure of } & \\
Sampling Adequacy. & 0.663 \\
\hline $\begin{array}{l}\text { Bartlett's Test of } \\
\text { Sphericity }\end{array}$ & $\begin{array}{l}\text { Approx. Chi- } \\
\text { Square }\end{array}$ & 777.732 \\
\hline & Df & 300 \\
\hline & Sig. & .000 \\
\hline
\end{tabular}

Tabel 3. KMO and Bartlett's Test data orang tua

\begin{tabular}{|l|l|r|}
\hline \multicolumn{2}{|l|}{$\begin{array}{l}\text { Kaiser-Meyer-Olkin Measure of } \\
\text { Sampling Adequacy. }\end{array}$} & 0.632 \\
\hline $\begin{array}{l}\text { Bartlett's Test of } \\
\text { Sphericity }\end{array}$ & $\begin{array}{l}\text { Approx. Chi- } \\
\text { Square }\end{array}$ & 556.000 \\
\hline & Df & 300 \\
\hline & Sig. & .000 \\
\hline
\end{tabular}

Dari Tabel 2 dan 3 KMO dan Bartlett's test telihat nilai Kaiser-Meyer-Olkin Measure of Sampling Adequacy yang data dari Kepala Sekolah adalah sebesar 0,663 dan data yang dari orang tua siswa adalah sebesar 0,632 yang berarti telah memenuhi kriteria persyaratan karena nilai diatas 0,5. Ini artinya ada korelasi antar indikator pembentuk faktor walaupun hanya sedikit variabel yang dapat dikelompokan. Dari hasil uji menunjukan bahwa bisa di analisis lanjut.

\subsubsection{Anti-Image Matrices}

Dalam penelitian ini nilai MSA, terdapat variabel yang memiliki nilai dibawah 0,5. Maka dilakukan pengulangan dengan mengeluarkan variabel 4, variabel 12, varabel 13, dan variabel 21, karena tidak memenuhi nilai MSA. Setelah variabel- variabel yang tidak memenuhi nilai MSA dikeluarkan, maka penelitian ini bisa dilanjutkan karena semua variabel memiliki nilai MSA telah $\geq 0,5$. Karena jumlah variabel telah berkurang maka nilai dari KMO dan Barttlet test telah berubah seperti pada Tabel 4.:

Tabel 4 : KMO and Bartlett's Test data Kepala Sekolah

\begin{tabular}{|l|l|r|}
\hline Kaiser-Meyer-Olkin Measure of Sampling Adequacy. & .745 \\
\hline Bartlett's Test of Sphericity & Approx. Chi-Square & 563.409 \\
\cline { 2 - 3 } & Df & 210 \\
\cline { 2 - 3 } & Sig. & .000 \\
\hline
\end{tabular}

\subsubsection{Communalities}

Setelah data dalam penelitian telah memenuhi uji KMO dan Bartlett's selanjutnya dilakukan proses faktorisasi (factoring). Communalities menerangkan berapa persen variabel yang akan membentuk faktor. Angka 0 dapat mengetahui varian suatu faktor dengan masing-masing faktor mempunyai angka mendekati nilai 1 yang menunjukan jumlah varian faktor tersebut. Jumlah nilai varian yang mendekati nilai 1 menunjukan semakin baik faktor tersebut menjelaskan varian dari variabelnya.

\subsubsection{Total Variance Explained \\ 6.2.4.1. Data Kepala sekolah}

Bila nilai initial eigevalues $\geq 1$, maka faktor tersebut dapat menjelaskan variabel dengan baik sehingga perlu diikutsertakan dalam pembentukan variabel (Widarjono,2010). Sebaliknya jika initial eigenvalues $<1$, faktor tersebut tidak dapat menjelaskan variabel dengan baik sehingga tidak diikut sertakan dalam pembentukan variabel. Dalam penelitian ini diperoleh nilai initial eigenvalues yang membentuk 6 faktor, dengan masing-masing faktor mempunyai nilai eigenvalues 
7.837, 2.273, 1.805, 1.505, 1.231, dan 1.050. Sesuai jumlah faktor yang terbentuk, selanjutnya dapat dijelaskan faktor yang terbentuk.

- Jika 21 variabel di ekstrak menjadi 1 faktor, maka : 7.837/21 x 100\% $=37.319 \%$, artinya jika 21 variabel tersebut dijadikan 1 faktor maka faktor tersebut hanya mampu menjelaskan varian variabelnya sebesar $37.319 \%$

- Jika 21 variabel di ekstrak menjadi 2 faktor, maka : $2.273 / 21 \times 100 \%=10.823 \%$ artinya jika 21 variabel tersebut dijadikan 1 faktor maka faktor tersebut mampu menjelaskan varian variabelnya sebesar $10.823 \%$

- Jika 21 variabel diekstrak menjadi 3 faktor, maka : 1.805/21 x 100\% $=8.595 \%$

- Jika 21 variabel diekstrak menjadi 4 faktor, maka : $1.505 / 21 \times 100 \%=7.167 \%$

- Jika 21 variabel diekstrak menjadi 5 faktor, maka : $1.231 / 21 \times 100 \%=6.146 \%$

- Jika 21 variabel diekstrak menjadi 6 faktor, maka : 1.205/21 x 100\% $=5.738 \%$

Karena dalam penelitian ini memperoleh 6 faktor maka 6 faktor tersebut mampu menjelaskan sebesar $75.788 \%$ yang di peroleh dari total varian dari 21 variabel yang ada $(5.738 \%$ $+6.146 \%+7.167 \%+8.595 \%+10.823 \%+37.319 \%)$.

\subsubsection{Data Orang Tua}

Proses pengujian dan menentukan faktor yang terbentuk dari total variances explain dari data Orang tua dalam penelitian ini dilakukan seperti langkah-langkah pada data Kepala Sekolah. Hasil dari data dalam penelitian bisa dilihat pada Lampiran 3 dimana nilai communalities variabel 1 adalah 0.711 . Hal ini berarti sekitar $71.1 \%$ varian dari variabel 1 bisa dijelaskan oleh faktor yang terbentuk. Begitu juga untuk nilai communalities dari variabel selanjutnya dapat menerangkan persentase varian dari variabel tersebut dengan semakin dekat nilai dari communalities sebuah variabel maka semakin erat hubungannya dengan faktor yang akan terbentuk.

Dalam data ini diperoleh total variance explained membentuk 4 faktor. Sesuai jumlah faktor yang terbentuk, selanjutnya dijelaskan faktor yang terbentuk.

- Jika 16 variabel diekstrak menjadi 3 faktor, maka : $6.939 / 16 \times 100 \%=43.368 \%$

- Jika 16 variabel diekstrak menjadi 4 faktor, maka : $1.531 / 16$ x $100 \%=9.568 \%$

- Jika 16 variabel diekstrak menjadi 5 faktor, maka : $1.376 / 16$ x $100 \%=8.6 \%$

- Jika 16 variabel diekstrak menjadi 6 faktor, maka : $1.182 / 16$ x $100 \%=7.387 \%$

Karena memperoleh 4 faktor maka 4 faktor tersebut mampu menjelaskan sebesar $68,923 \%$ yang di peroleh dari total varian dari 25 variabel yang ada.

\subsubsection{Rotasi Faktor}

\subsubsection{Data Kepala Sekolah}

Dalam penelitian ini digunakan metode rotasi varimax. Tujuan dari rotasi varimax adalah berusaha meminimumkan banyaknya variabel dengan muatan tinggi (high loading) pada suatu faktor yang terbentuk, dengan demikian memudahkan dalam pembuatan interpretasi mengenai faktor karena variabel yang masuk dalam faktor tertentu dapat terlihat dengan jelas.

Tabel 5 : Rotasi Matriks Komponen (a) data Kepala Sekolah

\begin{tabular}{|c|c|c|c|c|c|c|c|c|c|c|c|c|c|}
\hline & \multicolumn{6}{|c|}{ Component } & VAR 15 & .644 & .392 & -.028 & .173 & -.111 & .263 \\
\hline & 1 & 2 & 3 & 4 & 5 & 6 & VAR 16 & .662 & .026 & .472 & .287 & .032 & .060 \\
\hline VAR 1 & .777 & .320 & .231 & .135 & .269 & .065 & VAR 17 & .013 & .096 & .738 & .377 & -.122 & -.057 \\
\hline VAR 2 & .852 & -.081 & .287 & .038 & .100 & -.177 & VAR 18 & .688 & .206 & -.075 & .158 & .049 & .126 \\
\hline VAR 3 & .299 & -.047 & .830 & -.034 & .274 & .068 & VAR 19 & .479 & .303 & .002 & .110 & .613 & .016 \\
\hline VAR 5 & .117 & .172 & .875 & .098 & .204 & -.135 & VAR 20 & .186 & .537 & .101 & .173 & .042 & -.550 \\
\hline VAR 6 & .259 & .224 & .236 & .767 & -.057 & -.001 & VAR 22 & -.014 & .157 & .087 & .019 & .722 & .247 \\
\hline VAR 7 & .204 & .322 & -.068 & .739 & .447 & -.022 & VAR 23 & .055 & -.052 & .177 & .260 & .824 & -.031 \\
\hline VAR 8 & .236 & .769 & -.126 & .096 & .089 & .134 & VAR 24 & .202 & .150 & -.099 & .131 & .130 & .804 \\
\hline VAR 9 & .240 & .603 & .163 & .229 & .484 & -.168 & VAR25 & .110 & .094 & .158 & .692 & .242 & .129 \\
\hline VAR 10 & .092 & .770 & .236 & .244 & .064 & .077 & & & & & & & \\
\hline VAR 11 & .139 & .510 & .199 & .221 & .305 & .478 & & & & & & & \\
\hline VAR 14 & .604 & .308 & .203 & .565 & .186 & .134 & & & & & & & \\
\hline
\end{tabular}

Dengan melihat Tabel 5 dapat ditentukan yang mana masuk atau berkorelasi kuat dengan faktorfaktor yang ada. Faktor-faktor ini yang dikatakan penentu mutu pendidikan sekolah dasar. 
1. Faktor 1 terdiri dari variabel $1,2,14$, 15, 16, dan 18

3. Faktor 3 terdiri dari variabel 3,5 dan 17

4. Faktor 4 terdiri dari variabel 6,7 dan 25

2. Faktor 2 terdiri dari variabel $8,9,10$, 11 dan 20

5. Faktor 5 terdiri dari variabel 19,22 dan 23

6. Faktor 6 terdiri dari variabel 24

\subsubsection{Data Orang Tua}

Tabel 6 : Rotasi Martiks Komponen (a) data Orang Tua

\begin{tabular}{|c|c|c|c|c|}
\hline \multirow{2}{*}{} & \multicolumn{4}{|c|}{ Component } \\
\cline { 2 - 5 } & 1 & 2 & 3 & 4 \\
\hline VAR 1 & .292 & .045 & .787 & -.073 \\
\hline VAR 2 & .504 & .112 & .524 & .028 \\
\hline VAR 3 & .764 & .278 & -.069 & .331 \\
\hline VAR 4 & .776 & .167 & .282 & .019 \\
\hline VAR 5 & .865 & .225 & .110 & .240 \\
\hline VAR 6 & .771 & .297 & .251 & -.056 \\
\hline VAR 7 & .470 & .460 & .456 & -.094 \\
\hline
\end{tabular}

\begin{tabular}{|c|c|c|c|c|}
\hline VAR 8 & .579 & .659 & -.026 & .014 \\
\hline VAR 9 & .402 & .779 & .058 & -.114 \\
\hline VAR 10 & .223 & .744 & .358 & -.090 \\
\hline VAR 11 & .261 & .684 & .312 & -.010 \\
\hline VAR 12 & -.031 & .674 & .069 & .431 \\
\hline VAR 14 & .174 & .635 & .103 & .127 \\
\hline VAR 16 & .278 & .386 & .394 & .479 \\
\hline VAR 19 & -.102 & .294 & .739 & .160 \\
\hline VAR 24 & .127 & -.054 & -.022 & .828 \\
\hline
\end{tabular}

1. Faktor 1 terdiri dari variabel 3, 4, 5, 6 dan 7

2. Faktor 2 terdiri dari variabel $8,9,10,11,12$ dan 14

3. Faktor 3 terdiri dari variabel 1,2 dan 19

4. Faktor 4 terdiri dari variabel 24

\subsubsection{Interpretasi Faktor}

Dengan melihat total variance explained, grafik screen plot, dan rotated component matrix, maka langkah selanjutnya dalam penelitian ini adalah menginterpretasikan hasil analisis faktor diperoleh 6 faktor dari data kepala sekolah yang dapat mewakili ke 25 variabel dan interpretasi dari 9 faktor dari data orang tua siswa yang mewakili 25 variabel yang di analisis, yaitu :

\subsubsection{Data Kepala Sekolah}

1. Faktor pertama $\left(\mathrm{F}_{1}\right)$ adalah standar sarana dan pransarana dengan kontribusi sebesar $37.319 \%$, seperti pada Tabel 7.

2. Faktor kedua $\left(\mathrm{F}_{2}\right)$ adalah standar pendidik dan tenaga kependidikan dengan kontribusi sebesar $10.823 \%$, seperti pada Tabel 8.

3. Faktor ketiga $\left(\mathrm{F}_{3}\right)$ adalah standar isi dengan kontribusi sebesar $8.595 \%$, seperti pada Tabel 9 .

4. Faktor empat $\left(\mathrm{F}_{4}\right)$ adalah standar penilaian dengan kontribusi sebesar $7.167 \%$, seperti pada Tabel 10.

5. Faktor kelima $\left(\mathrm{F}_{5}\right)$ adalah standar pengelolaan dengan kontribusi sebesar $6.146 \%$, seperti pada Tabel 11.

6. Faktor keenam $\left(\mathrm{F}_{6}\right)$ adalah standar pembiayaan dengan kontribusi sebesar $5.738 \%$, seperti pada Tabel 12.

Tabel 7 : Interpretasi Faktor $\left(\mathrm{F}_{1}\right)$

\begin{tabular}{|c|l|r|}
\hline Urutan & Variabel & $\begin{array}{l}\text { Nilai } \\
\text { loading }\end{array}$ \\
\hline 1 & Kondisi sekolah (X2) & .852 \\
\hline 2 & $\begin{array}{l}\text { Sarana dan Prasarana sekolah } \\
(\mathrm{X} 1)\end{array}$ & .777 \\
\hline 3 & Peningkatan hasil belajar (X18) & .688 \\
\hline 4 & Kinerja visi dan misi (X16) & .662 \\
\hline 5 & Pengembangan Potensi (X15) & .644 \\
\hline 6 & Pencapaian peserta didik (X14) & .604 \\
\hline
\end{tabular}

Tabel 8 : Interpretasi Faktor $\left(\mathrm{F}_{2}\right)$

\begin{tabular}{|c|l|r|}
\hline Urutan & Variabel & $\begin{array}{l}\text { Nilai } \\
\text { loading }\end{array}$ \\
\hline 1 & Prestasi sekolah (X10) & .770 \\
\hline 2 & $\begin{array}{l}\text { Penerapkan prinsip-prinsip PAKEM/ } \\
\text { CTL (X8) }\end{array}$ & .769 \\
\hline 3 & Kebutuhan semua peserta didik (X9) & .603 \\
\hline 4 & $\begin{array}{l}\text { Pengembangan profesi bagi para } \\
\text { pendidik dan tenaga kependidikan } \\
\text { (X20) }\end{array}$ & .537 \\
\hline 5 & $\begin{array}{l}\text { Penilaian dalam bidang akademik } \\
\text { maupun non akademik (X11) }\end{array}$ \\
\hline
\end{tabular}


Tabel 9 : Interpretasi Faktor $\left(\mathrm{F}_{3}\right)$

\begin{tabular}{|l|l|r|}
\hline Urutan & Variabel & $\begin{array}{l}\text { Nilai } \\
\text { loading }\end{array}$ \\
\hline 1 & Silabus (X5) & .875 \\
\hline 2 & Kurikulum sekolah (X3) & .830 \\
\hline 3 & Perbaikan kinerja (X17) & .738 \\
\hline
\end{tabular}

Tabel 10 : Interpretasi Faktor $\left(\mathrm{F}_{4}\right)$

\begin{tabular}{|l|l|r|}
\hline Urutan & Variabel & $\begin{array}{l}\text { Nilai } \\
\text { loading }\end{array}$ \\
\hline 1 & RPP pembelajaran (X6) & .767 \\
\hline 2 & $\begin{array}{l}\text { Sumber belajar untuk } \\
\text { pembelajaran dapat diperoleh dan } \\
\text { digunakan secara tepat (X7) }\end{array}$ & .739 \\
\hline 3 & $\begin{array}{l}\text { Penjaminan kesetaraan akses } \\
(\mathrm{X} 25)\end{array}$ & .692 \\
\hline
\end{tabular}

Tabel 11 : Interpretasi Faktor $\left(\mathrm{F}_{5}\right)$

\begin{tabular}{|l|l|r|}
\hline Urutan & Variabel & $\begin{array}{l}\text { Nilai } \\
\text { loading }\end{array}$ \\
\hline 1 & Pengelolaan Keuangan (X23) & .824 \\
\hline 2 & $\begin{array}{l}\text { Jumlah pendidik dan tenaga } \\
\text { kependidikan (X22) }\end{array}$ & .722 \\
\hline 3 & $\begin{array}{l}\text { Pengumpulan dan penggunaan } \\
\text { data (X19) }\end{array}$ & .613 \\
\hline
\end{tabular}

Tabel 12 : Interpretasi Faktor $\left(\mathrm{F}_{6}\right)$

\begin{tabular}{|l|lr|r|}
\hline Urutan & Variabel & $\begin{array}{l}\text { Nilai } \\
\text { loading }\end{array}$ \\
\hline 1 & $\begin{array}{l}\text { Tambahan } \\
\text { pembiayaan (X24) }\end{array}$ & dukungan & .804 \\
\hline
\end{tabular}

\subsubsection{Data Orang Tua}

1. Faktor pertama $\left(F_{1}\right)$ adalah standar isi dengan kontribusi sebesar $43.368 \%$, seperti pada Tabel 13.

2. Faktor ke dua $\left(\mathrm{F}_{2}\right)$ adalah standar proses dengan kontribusi sebesar $9.568 \%$, seperti pada Tabel 14.

3. Faktor ke tiga $\left(\mathrm{F}_{3}\right)$ adalah standar sarana dan prasarana dengan kontribusi sebesar $8.6 \%$, seperti pada Tabel 15.

4. Faktor ke empat $\left(\mathrm{F}_{4}\right)$ adalah standar pembiayayaan dengan kontribusi sebesar $7.387 \%$, seperti pada Tabel 16.

Tabel 13 : Interpretasi Faktor $\left(\mathrm{F}_{1}\right)$

\begin{tabular}{|l|l|r|}
\hline Urutan & Variabel & $\begin{array}{l}\text { Nilai } \\
\text { Loading }\end{array}$ \\
\hline 1 & Silabus (X5) & .865 \\
\hline 2 & $\begin{array}{l}\text { Penyediaan kebutuhan dalam } \\
\text { pengembangan diri peserta didik } \\
\text { X4) }\end{array}$ & .776 \\
\hline 3 & RPP pembelajaran (X6) & .771 \\
\hline 4 & Kurikulum sekolah (X3) & .764 \\
\hline 5 & $\begin{array}{l}\text { Sumber belajar untuk pembelajaran } \\
\text { dapat diperoleh dan digunakan secara } \\
\text { tepat (X7) }\end{array}$ & .470 \\
\hline
\end{tabular}

Tabel 15 : Interpretasi Faktor $\left(\mathrm{F}_{3}\right)$

\begin{tabular}{|l|l|r|}
\hline Urutan & Variabel dan Prasarana & Nilai Loading \\
\hline 1 & $\begin{array}{l}\text { Sarana dan } \\
\text { sekolah (X1) }\end{array}$ & .787 \\
\hline 2 & $\begin{array}{l}\text { Pengumpulan dan } \\
\text { penggunaan data (X19) }\end{array}$ & .739 \\
\hline 3 & Kondisi sekolah (X2) & .524 \\
\hline
\end{tabular}

Tabel 14 : Interpretasi Faktor $\left(\mathrm{F}_{2}\right)$

\begin{tabular}{|l|l|l|}
\hline Urutan & Variabel & $\begin{array}{l}\text { Nilai } \\
\text { Loading }\end{array}$ \\
\hline 1 & $\begin{array}{l}\text { Kebutuhan semua peserta didik } \\
(\text { X9) }\end{array}$ & .779 \\
\hline 2 & Prestasi sekolah (X10) & .744 \\
\hline 3 & $\begin{array}{l}\text { Penilaian dalam bidang akademik } \\
\text { maupun non akademik (X11) }\end{array}$ & .684 \\
\hline 4 & $\begin{array}{l}\text { Penilaian berdampak pada proses } \\
\text { belajar (X12) }\end{array}$ & .674 \\
\hline 5 & $\begin{array}{l}\text { Penerapkan prinsip-prinsip } \\
\text { PAKEM/ CTL (X8) }\end{array}$ & .659 \\
\hline 6 & Pencapaian peserta didik (X14) & .635 \\
\hline
\end{tabular}

Tabel 16 : Interpretasi Faktor $\left(\mathrm{F}_{4}\right)$

\begin{tabular}{|l|l|l|}
\hline Urutan & Variabel & $\begin{array}{l}\text { Nilai } \\
\text { Loading }\end{array}$ \\
\hline 1 & $\begin{array}{l}\text { Tambahan dukungan pembiayaan } \\
(\mathrm{X} 24)\end{array}$ & .828 \\
\hline
\end{tabular}

\section{Kesimpulan}

1. Dari hasil penelitian diperoleh 6 faktor penentu mutu pendidikan Sekolah Dasar Negeri di kota Manado. Hasil ektraksi dari analisis faktor yaitu faktor sarana dan prasarana, standar isi, standar pendidik dan tenaga pendidikan, standar pembiayaan, standar pengelolaan, standar penilaian dan standar proses

2. Varian faktor dari Mutu Sekolah Dasar Negeri di Kota Manado sebesar $75.788 \%$, dengan faktor standar sarana dan prasarana memiliki kontribusi sebesar $37.319 \%$. 
3. Mutu pendidikan Sekolah Dasar Negeri di Kota Manado menurut orang tua siswa memperoleh 4 faktor penentu mutu pendidikan dengan varian faktor sebesar 68,923\%. Faktor yang dominan yaitu faktor standar isi dengan kontribusi sebesar $43.368 \%$.

\section{Saran}

Karena Sekolah Dasar Swasta memiliki peminat yang besar, maka perlunya penelitian dilanjutkan untuk Sekolah Dasar Swasta agar dapat melihat perbedaan dengan Sekolah Dasar Negeri. Kurangnya keterbukaan dan ketidaktauhan responden dalam memberikan data maka sebaiknya setiap indikator kunci pencapaian 8 standar Nasional pendidikan Sekolah Dasar harusnya dirincikan. Pendidikan Sekolah Dasar harus terus dikembangkan dan ditingkatkan dalam proses kinerja, konsistensi, pelayanan, sarana dan prasarana serta pembiayaan.

\section{Daftar Pustaka}

[1] Mohyani. 2013. Indikator Kunci Pencapaian 8 Standar Nasional Pendidikan SD/MI. http://mohyani69.file.wordpress.com. [Oktober 2010]

[2] Imam, S. 2009. Analisis Hubungan Rata-Rata IPK dan Lama Studi Mahasiswa ITS Dengan Menggunakan Analisis Faktor [Skripsi]. Institut Teknologi Sepuluh Nopember.

[3] Lombone, I. 2012. Tingkat Kepuasan Mahasiswa Terhadap Pelayanan Universitas Sam Ratulangi Menggunakan Analisis Faktor [Skripsi]. FMIPA UNSRAT. Manado.

[4] Mamahit, S. 2013. Tingkat Kepuasan Dosen dan Tenaga Kependidikan Terhadap Pelayanan Universitas Sam Ratulangi Menggunakan Analisis Faktor. Jurnal Ilmiah Sains 13(1):38 - 44.

[5] Supranto, J. 2004. Analisis Multivariat Arti dan Interpretasi. Rineka Cipta. Jakarta. 